\title{
KAJIAN BASIS DAN PRIORITAS DALAM SEKTOR PERTANIAN BAGI PEMBANGUNAN WILAYAH PESISIR BENGKULU
}

\section{STUDY OF BASIS AND PRIORITY IN AGRICULTURAL SECTOR FOR COASTAL AREA DEVELOPMENT IN BENGKULU}

\author{
Melli Suryanty, Sriyoto, Ellys Yuliarti \\ Jurusan Sosial Ekonomi Pertanian Fakultas Pertanian \\ Universitas Bengkulu
}

\begin{abstract}
The objectives of this research were to identify agriculture subsectors that can be the sector basis for the region development, and give information about priority scale of agriculture subsectors development in Bengkulu region development planning. This research used the secondary data gained from time series data from year 2000-2011. Analysis methods used in this research were sector contribution, location quotient, and shift share analysis. The results of the research showed that fishery subsector gave significant contribution for Bengkulu City PDRB. Fishery subsector became the basis and main priority of the agriculture development in year 2000-2011. This was shown from the biggest contribution value, location quotient value was greater than 1, and positive shift share value. The main priority of agriculture sector development is fishery, livestock, food plant, and estate subsector.
\end{abstract}

Keywords: Basic sector, agricultural sector, regional development.

\section{PENDAHULUAN}

Pembangunan pertanian telah memberikan sumbangan besar dalam pembangunan nasional, seperti pembentukan Produk Domestik Bruto (PDB), penyerapan tenaga kerja, peningkatan pendapatan masyarakat, perolehan devisa bagi negara melalui ekspor dan penekanan inflasi. Pembangunan sektor pertanian mempunyai keterkaitan yang erat dengan sektor-sektor lain seperti: sebagai penyedia bahan makanan dan bahan baku yang digunakan sektor industri, serta sebagai sumber modal untuk investasi ekonomi (Tohir, 2008).

Hasil pembangunan yang dilakukan oleh setiap wilayah/daerah dapat dilihat dari besarnya terhadap Produk Domestik Regional Bruto (PDRB). PDRB sebagai salah satu alat ukur untuk mengetahui struktur ekonomi suatu wilayah, diyakini masih merupakan indikator penting dalam menentukan arah

44 | Melli Suryanty, Sriyoto, Ellys Yuliarti, Kajian Basis dan Prioritas ... 
pembangunan. Dengan memperhatikan besarnya peranan masing-masing sektor dalam PDRB suatu wilayah, maka skala prioritas pembangunan pada suatu wilayah dapat ditentukan (Widodo, 1990). Sektor pertanian di Provinsi Bengkulu, misalnya, memiliki peranan yang penting dalam suatu perekonomian, karena merupakan sektor utama yang memberikan kontribusi terbesar dalam pembentukan Produk Domestik Regional Bruto (PDRB) yaitu sebesar 39,90\% pada tahun 2010 (BPS Provinsi Bengkulu, 2011).

Kota Bengkulu sebagai salah satu wilayah yang berada di pesisir pantai dan juga merupakan ibukota Provinsi Bengkulu memberikan pengaruh yang besar bagi aktivitas perekonomian Provinsi Bengkulu. Dengan posisi wilayah pesisir pantai Kota Bengkulu, maka subsektor perikanan atau kelautan mengunggul dari subsektor lainnya dalam memberikan sumbangsih bagi pendapatan daerah. Namun, subsektor tersebut belum tentu dapat menjadi basis subsektor unggulan bagi sektor pertanian di Kota Bengkulu. Perkembangan laju pertumbuhan PDRB Kota Bengkulu kurun waktu terakhir menunjukkan adanya peningkatan. Pada tahun 2011 laju pertumbuhan PDRB mencapai $6,66 \%$ dan angka ini naik sebesar 0,3 poin dari presentase laju pertumbuhan PDRB tahun 2010, yakni sebesar 6,36 persen (BPS Provinsi Bengkulu, 2012).

Penelitian ini bertujuan untuk mengidentifikasi subsektor pertanian, subsektor pertanian yang dapat menjadi kontribusi basis sektor bagi pembangunan wilayah, dan menghasilkan informasi untuk prioritas pembangunan subsektor pertanian dalam pembangunan wilayah Kota Bengkulu.

\section{METODE PENELITIAN}

Penelitian ini dilakukan di Kota Bengkulu, Provinsi Bengkulu yang berlangsung dari bulan Juli sampai November 2013. Pemilihan lokasi/daerah penelitian dilakukan secara sengaja (purposive). Data yang diambil adalah data time series dari tahun 2000-2011. Besarnya kontribusi subsektor pertanian dihitung dengan rumus yang diformulasikan oleh Widodo (1990):

$$
\mathrm{K}_{\mathrm{si}}=\frac{X i}{Y} \times 100 \%
$$

dimana $\mathrm{K}_{\mathrm{si}}$ adalah kontribusi subsektor pertanian i terhadap sektor pertanian $(\%), X_{i}$ adalah pendapatan subsektor pertanian, dan $Y$ adalah PDRB sektor pertanian

Untuk mengetahui sektor basis dan non-basis dari subsektor pertanian dapat diidentifikasi dengan menggunakan rumus LQ (Richardson, 2001):

$$
L Q=\frac{S i / N i}{S / N} \quad \text { atau } L Q=\frac{S i / S}{N i / N}
$$


Dimana LQ adalah Besarnya Location Quotient, Si adalah Jumlah pendapatan subsektor i kota Bengkulu, S adalah Total Pendapatan sektor pertanian Kota Bengkulu, Ni adalah Jumlah pendapatan subsektor pertanian, i Provinsi Bengkulu, dan Nadalah Total pendapatan sektor pertanian Provinsi Bengkulu

$$
\begin{aligned}
\text { Jika LQ }>1 & \longrightarrow \text { termasuk sektor basis } \\
\mathrm{LQ} \leq 1 & \longrightarrow \text { termasuk sektor non-basis }
\end{aligned}
$$

Untuk melihat laju pertumbuhan sektor pertanian di Provinsi Bengkulu digunakan analisis Shift Share. Analisis ini menggunakan metode pengisolasian berbagai faktor penyebab perubahan struktur industri suatu daerah dalam pertumbuhan dari satu kurun waktu ke kurun waktu yang lain (Tarigan, 2006).

\section{Analisis Basis Sektor Pertanian: Pendekatan Shift Share}

Analisis Shift share untuk melihat laju pertumbuhan sektor pertanian di Kota Bengkulu dan Provinsi Bengkulu. Metode ini lebih tajam dibandingkan dengan metode $L Q$, dimana metode ini memerinci penyebab perubahan atas beberapa variabel. Analisis ini menggunakan metode pengisolasian berbagai faktor yang menyebabkan perubahan struktur industri suatu daerah dalam pertumbuhannya dari satu kurun waktu ke kurun waktu yang lain (Tarigan, 2008).

$$
\begin{aligned}
\Delta E_{r, i, t} & =\left(N_{S t}+P_{i}+D_{r}\right) \\
N s & =E_{r, i, t-n}\left(E_{N, t} / E_{N, t-n}\right)-E_{r, i, t-n} \\
P_{r, i, t} & =\left\{\left(E_{r, i, t} / E_{N, i, t-n}\right)-\left(E_{N, t-n}\right)\right\} x E_{r, i, t-n} \\
D_{r, i, t} & =\left\{E_{r, i, t}-\left(E_{N, i, t} / E_{N, i, t-n}\right)-E_{r, i, t-n}\right\}
\end{aligned}
$$

Dimana $\Delta$ adalah Pertambahan, angka akhir tahun (tahun $\mathrm{t}$ ) dikurangi dengan angka awal (tahun t-n), Nadalah Provinsi Bengkulu,r adalah Kota Bengkulu, Eadalah Employment atau banyaknya penyerapan tenaga kerja, i adalah Subsektor pertanian i, t-n adalah Tahun awal, Ns adalah National share, Padalah Propotional share, dan D adalah Differential shift.

\section{HASIL DAN PEMBAHASAN}

\section{Analisis Kontribusi Subsektor}

Kontribusi subsektor pertanian memberikan gambaran tentang sumbangan subsektor pertanian yang terlihat dalam Produk Domestik Regional Bruto (PDRB) atas dasar harga konstan ataupun harga yang berlaku dari tahun 2000-2011. Nilai kontribusi subsektor pertanian di Kota Bengkulu periode 2000-2011 dengan pendekatan PDRB konstan dan berlaku disajikan dalam Tabel 1. 
Dari Tabel 1 dapat diketahui bahwa baik berdasarkan harga konstan dan harga berlaku, subsektor perikanan memberikan kontribusi terhadap sektor pertanian di setiap tahunnya dan secara rata-rata menunjukkan hal yang sama. Hal ini berarti bahwa subsektor perikanan menjadi subsektor basis dalam pengembangan sektor pertanian di Kota Bengkulu, subsektor peternakan menempati urutan kedua, kemudian disusul oleh subsektor tanaman bahan makanan dan subsektor perkebunan yang memberikan kontribusi relatif kecil baik di setiap tahunnya maupun secara rata-rata yang dilihat berdasarkan atas harga konstan ataupun harga berlaku.

Tabel 1. Kontribusi Subsektor Pertanian di Kota Bengkulu Periode 20002011 dengan Pendekatan PDRB Konstan dan Berlaku

\begin{tabular}{ccccccccc}
\hline \multirow{2}{*}{ Tahun } & \multicolumn{2}{c}{ TBM (\%) } & \multicolumn{2}{c}{ Perkebunan (\%) } & \multicolumn{2}{c}{ Peternakan (\%) } & \multicolumn{2}{c}{ Perikanan (\%) } \\
\cline { 2 - 8 } & Konstan & Berlaku & Konstan & Berlaku & Konstan & Berlaku & Konstan & Berlaku \\
\hline $\mathbf{2 0 0 0}$ & 10,81 & 10,81 & 0,08 & 0,08 & 11,53 & 11,53 & 77,58 & 77,58 \\
$\mathbf{2 0 0 1}$ & 11,00 & 10,72 & 0,09 & 0,07 & 11,62 & 11,06 & 77,29 & 78,15 \\
$\mathbf{2 0 0 2}$ & 10,75 & 10,19 & 0,11 & 0,08 & 11,50 & 10,41 & 77,64 & 79,32 \\
$\mathbf{2 0 0 3}$ & 10,51 & 9,76 & 0,14 & 0,10 & 11,32 & 10,68 & 78,05 & 79,46 \\
$\mathbf{2 0 0 4}$ & 10,22 & 8,99 & 0,15 & 0,10 & 10,72 & 10,00 & 78,91 & 80,92 \\
$\mathbf{2 0 0 5}$ & 9,90 & 8,24 & 0,16 & 0,11 & 10,26 & 9,47 & 79,68 & 82,19 \\
$\mathbf{2 0 0 6}$ & 9,56 & 7,87 & 0,16 & 0,11 & 10,18 & 9,36 & 80,10 & 82,66 \\
$\mathbf{2 0 0 7}$ & 9,36 & 7,87 & 0,16 & 0,12 & 10,11 & 9,36 & 80,37 & 82,66 \\
$\mathbf{2 0 0 8}$ & 8,64 & 7,38 & 0,16 & 0,10 & 10,32 & 9,46 & 80,53 & 83,05 \\
$\mathbf{2 0 0 9}$ & 8,44 & 6,83 & 0,18 & 0,10 & 10,23 & 9,86 & 80,62 & 83,22 \\
$\mathbf{2 0 1 0}$ & 8,41 & 6,90 & 0,18 & 0,09 & 10,37 & 9,82 & 80,35 & 83,19 \\
$\mathbf{2 0 1 1}$ & 8,49 & 6,76 & 0,19 & 0,09 & 11,18 & 9,69 & 80,14 & 83,46 \\
\hline Rata-2 & 9,67 & 8,53 & 0,15 & 0,10 & 10,78 & 10,06 & 79,27 & 81,32 \\
\hline \multicolumn{7}{c}{ Sumber: data sekunder diolah, 2013 }
\end{tabular}

Hal menarik temuan penelitian ini adalah adanya perbedaan trend dari setiap subsektor pertanian yang ditunjukkan oleh adanya sebaran data selama periode 2000-2011. Subsektor perikanan dan perkebunan cenderung memiliki trend peningkatan nilai kontribusi di setiap tahunnya, hal ini menunjukkan bahwa di masa yang akan datang dua subsektor ini mempunyai peluang besar untuk berkembang. Subsektor peternakan memiliki trend yang cenderung stabil (konstan) artinya tidak memperlihatkan peningkatan ataupun penurunan yang signifikan di setiap tahunnya. Hal ini mengindikasikan bahwa pengembangan subsektor peternakan dalam kurun waktu 12 tahun terakhir belum memberikan dampak yang signifikan dalam peningkatan kontribusi PDRB Kota Bengkulu. 


\section{Analisis Basis Sektor Pertanian: Pendekatan Location Quotient (LQ)}

Nilai Location Quotient (LQ) memberikan gambaran kapasitas (keunggulan) ekspor perekonomian dasar dan derajat self sufficiency pada suatu sektor (Tarigan, 2006). Dalam penelitian ini pendekatan LQ digunakan untuk menganalisis besarnya peranan subsektor pertanian di Kota Bengkulu terhadap besarnya peranan subssektor pertanian di Provinsi Bengkulu. Peranan subsubsektor pertanian di Kota Bengkulu dengan menggunakan perhitungan LQ berdasarkan indikator pendapatan. Mengenai gambaran sebaran nilai LQ subsektor pertanian di Kota Bengkulu periode 2000-2011 dengan indikator pendapatan pada harga konstan dan berlaku dapat terlihat pada Tabel 2 .

Tabel 2. Nilai LQ Subsektor Pertanian di Kota Bengkulu Periode 2000-2011 dengan Indikator Pendapatan pada Harga Konstan dan Harga Berlaku

\begin{tabular}{ccccccccc}
\hline \multirow{2}{*}{ Tahun } & \multicolumn{2}{c}{ TBM } & \multicolumn{2}{c}{ Perkebunan } & \multicolumn{2}{c}{ Peternakan } & \multicolumn{2}{c}{ Perikanan } \\
\cline { 2 - 8 } & Konstan & Berlaku & Konstan & Berlaku & Konstan & Berlaku & Konstan & Berlaku \\
\hline $\mathbf{2 0 0 0}$ & 0,228 & 0,228 & 0,0026 & 0,0026 & 1,645 & 1,645 & 7,131 & 7,131 \\
$\mathbf{2 0 0 1}$ & 0,234 & 0,214 & 0,0028 & 0,0026 & 1,673 & 1,699 & 7,144 & 6,912 \\
$\mathbf{2 0 0 2}$ & 0,245 & 0,177 & 0,0040 & 0,0026 & 1,776 & 1,299 & 7,180 & 7,210 \\
$\mathbf{2 0 0 3}$ & 0,237 & 0,180 & 0,0050 & 0,0036 & 1,726 & 1,353 & 6,892 & 6,935 \\
$\mathbf{2 0 0 4}$ & 0,224 & 0,186 & 0,0049 & 0,0041 & 1,441 & 1,495 & 6,970 & 7,104 \\
$\mathbf{2 0 0 5}$ & 0,218 & 0,177 & 0,0051 & 0,0041 & 1,393 & 1,418 & 7,043 & 7,130 \\
$\mathbf{2 0 0 6}$ & 0,213 & 0,172 & 0,0050 & 0,0041 & 1,370 & 1,373 & 7,003 & 7,007 \\
$\mathbf{2 0 0 7}$ & 0,207 & 0,173 & 0,0050 & 0,0040 & 1,388 & 1,344 & 7,142 & 7,095 \\
$\mathbf{2 0 0 8}$ & 0,192 & 0,159 & 0,0049 & 0,0042 & 1,426 & 1,323 & 7,385 & 5,931 \\
$\mathbf{2 0 0 9}$ & 0,185 & 0,139 & 0,0048 & 0,0043 & 1,394 & 1,231 & 8,109 & 6,777 \\
$\mathbf{2 0 1 0}$ & 0,185 & 0,133 & 0,0054 & 0,0043 & 1,363 & 1,121 & 8,371 & 7,057 \\
$\mathbf{2 0 1 1}$ & 0,131 & 0,128 & 0,0038 & 0,0040 & 1,020 & 0,770 & 6,033 & 5,363 \\
\hline Rata-2 & 0,208 & 0,172 & 0,0044 & 0,0037 & 1,468 & 1,339 & 7,200 & 6,804 \\
\hline$S$
\end{tabular}

Sumber: data sekunder diolah, 2013

Dari Tabel 2 terlihat bahwa subsektor perikanan dan peternakan merupakan subsektor basis karena memiliki LQ lebih besar dari 1 (satu). Dengan nilai LQ lebih besar dari 1 ini mengindikasikan bahwa subsektor ini yang menjadi penggerak bagi sektor pertanian di Kota Bengkulu. Nilai LQ pada subsektor tanaman bahan makanan dan perkebunan memiliki nilai kurang dari 1. Angka tersebut menunjukkan bahwa subsektor tanaman bahan makanan dan perkebunan bukan merupakan subsektor penggerak bagi sektor pertanian di Kota Bengkulu.

48 | Melli Suryanty, Sriyoto, Ellys Yuliarti, Kajian Basis dan Prioritas ... 


\section{Analisis Basis Sektor Pertanian: Pendekatan Shift Share}

Analisis ini bertujuan untuk membandingkan perbedaan laju pertumbuhan berbagai subsektor pertanian di Kota Bengkulu dengan Provinsi Bengkulu dan memperinci penyebab perubahan atas beberapa variabel. Analisis ini mengisolasi berbagai faktor yang menyebabkan perubahan struktur industri suatu daerah dalam pertumbuhannya dari suatu kurun waktu ke kurun waktu berikutnya. Dalam penelitian ini, analisis shift share menggunakan indikator pendapatan atas dasar konstan dan atas dasar harga berlaku. Pemilihan prioritas subsektor pertanian Kota Bengkulu disajikan pada Tabel 3.

Tabel 3. Pemilihan Prioritas Subsektor Pertanian Kota Bengkulu

\begin{tabular}{|c|c|c|c|c|c|c|}
\hline \multirow[b]{2}{*}{ Subsektor } & \multicolumn{3}{|c|}{ Shift Share } & \multirow{2}{*}{$\begin{array}{l}\text { Location } \\
\text { Quotient }\end{array}$} & \multirow[b]{2}{*}{ Kontribusi } & \multirow[b]{2}{*}{ Total } \\
\hline & $\begin{array}{c}\text { Differential } \\
\text { Shift }\end{array}$ & $\begin{array}{c}\text { Proportional } \\
\text { Share }\end{array}$ & $\begin{array}{c}\text { National } \\
\text { Share }\end{array}$ & & & \\
\hline 1.TBM & 0,052866 & 0,013662 & 0,006136 & 0,01316 & 0,007209 & 0,093033 \\
\hline 2.Perkebunan & 0,033108 & 0,009798 & 0,003599 & 0,01316 & 0,005913 & 0,065578 \\
\hline 3.Peternakan & 0,052866 & 0,018906 & 0,006136 & 0,02312 & 0,008667 & 0,109699 \\
\hline 4.Perikanan & 0,39516 & 0,095634 & 0,043129 & 0,13855 & 0,059211 & 0,731690 \\
\hline \multirow{3}{*}{ Total } & 0,534 & 0,138 & 0,059 & \multirow{2}{*}{0,188} & \multirow{2}{*}{0,081} & 1 \\
\hline & & 0,731 & & & & 1 \\
\hline & & & 1 & & & \\
\hline
\end{tabular}

Sumber: data sekunder diolah, 2013

Dari Tabel 3 dapat disimpulkan bahwa yang merupakan prioritas utama dari sektor pertanian Kota Bengkulu adalah subsektor perikanan karena memiliki nilai prioritas global yang paling besar, yaitu 0,731 yang dilihat dari kriteria shift share, location quotient dan kontribusi serta sub kriteria yaitu differential shift, propotional share dan national share. Yang menjadi prioritas kedua yaitu subsektor peternakan dengan nilai prioritas global sebesar 0,109. Subsektor yang menjadi prioritas ketiga adalah subsektor tanaman bahan makanan dengan nilai prioritas global sebesar 0,093. Sedangkan subsektor terakhir adalah subsektor perkebunan dengan nilai prioritas global terkecil sebesar 0,065.

Subsektor perikanan menjadi prioritas utama pada sektor pertanian di Kota Bengkulu, berarti subsektor perikanan adalah sebagai subsektor andalan yang memberikan pengaruh besar untuk perkembangan sektor pertanian di Kota Bengkulu. Dengan kata lain, bahwa Kota Bengkulu surplus akan subsektor perikanan. 


\section{SIMPULAN DAN IMPLIKASI KEBIJAKAN}

\section{Simpulan}

Berdasarkan hasil penelitian dan pembahasan dapat ditarik kesimpulan berikut: (a) Subsektor perikanan memberikan kontribusi yang sangat signifikan bagi PDRB Kota Bengkulu. Sedangkan subsektor lainnya kurang memberikan kontribusi bagi PDRB, (b) Selama periode tahun 2000-2011 dengan menggunakan indikator pendapatan atas dasar harga konstan dan berlaku subsektor perikanan menjadi basis dan prioritas utama dari pembangunan sektor pertanian di Kota Bengkulu, dan (Prioritas utama pembangunan sektor pertanian Kota Bengkulu adalah subsektor perikanan, peternakan, tanaman bahan makanan dan subsektor perkebunan.

\section{Implikasi Kebijakan}

Kesimpulan di atas mendasari implikasi-implikasi kebijakan bahwa subsektor perikanan sudah memiliki kontribusi yang cukup signifikan bagi PDRB, namun tidak halnya pada subsektor perkebunan, peternakan, dan tanaman bahan makanan. Subsektor perkebunan memiliki trend peningkatan nilai kontribusi di setiap tahunnya. Oleh karena itu, kebijakan pemerintah pada subsektor ini perlu ditingkatkan karena berpeluang untuk berkembang dan memberikan kontribusi yang besar bagi pendapatan daerah. Lebih lanjut, nilai kontribusi subsektor peternakan cenderung stabil (konstan) dan tidak memperlihatkan peningkatan ataupun penurunan yang signifikan, dengan kata lain kondisi ini menunjukkan bahwa pengembangan subsektor peternakan selama ini belum memberikan dampak yang signifikan dalam peningkatan PDRB. Oleh karena itu, pemerintah Kota Bengkulu perlu mengevaluasi kebijakkan sehingga dapat memberikan nilai kontribusi yang meningkat di masa mendatang. Sementara itu, subsektor tanaman bahan makanan memiliki trend nilai kontribusi menurun selama periode tahun pengamatan. Kondisi ini harus segera diantisipasi oleh pemerintah Kota Bengkulu dengan mengkaji dan mengevaluasi kebijakan yang telah ada khususnya kebijakkan pengembangan sektor ketahanan pangan.

50 | Melli Suryanty, Sriyoto, Ellys Yuliarti, Kajian Basis dan Prioritas ... 
ISSN: 1412-8837

\section{DAFTAR PUSTAKA}

BPS Provinsi Bengkulu. 2011. Bengkulu dalam Angka. BPS Provinsi Bengkulu. Bengkulu.

BPS Provinsi Bengkulu. 2012. Bengkulu dalam Angka. BPS Provinsi Bengkulu. Bengkulu.

Richardson, H. 2001. Dasar-Dasar Ilmu Ekonomi Regional. Jakarta: LPFEUI.

Tarigan, Robinson. 2006. Ekonomi Regional Teori dan Aplikasi. Jakarta: Bumi Aksara.

Aksara.

Tohir, K. 2008. Seuntai Pengetahuan tentang Usahatani Indonesia Bagian I. Jakarta: Bina Aksara.

Widodo, S.T. 1990. Indikator Ekonomi Dasar Perhitungan Perekonomian Indonesia. Yogyakarta: Kanisius. 